Im „Journal Club" werden Originalarbeiten aus der internationalen Fachliteratur referiert und kommentiert.

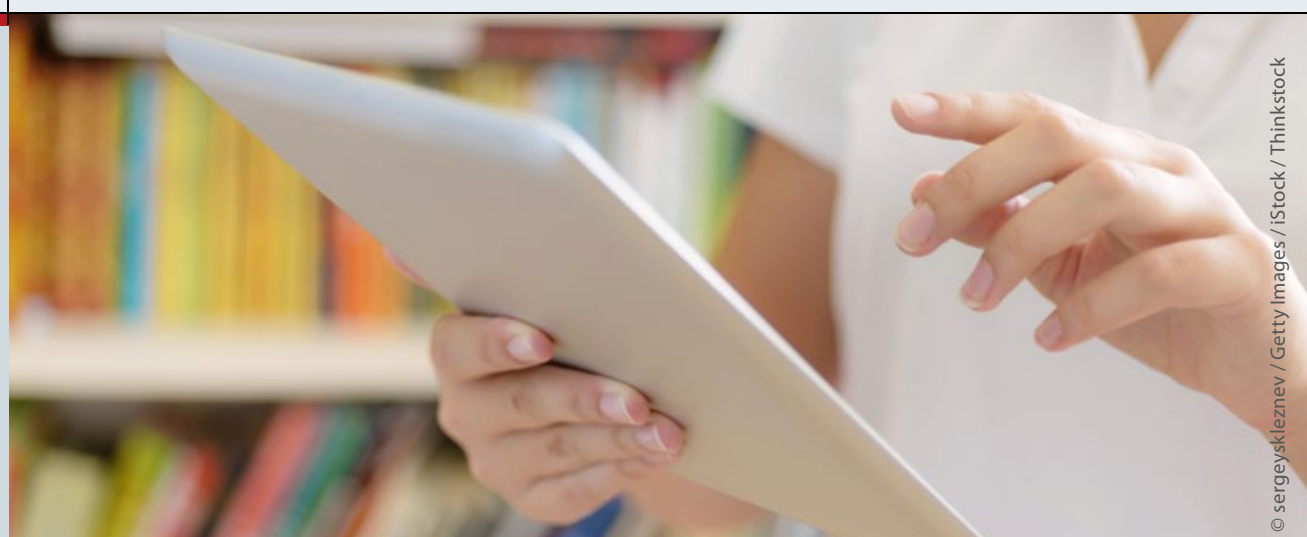

\section{Fertigmilch verändert Darmbesiedelung von Säuglingen}

\section{Welche Bakterien den Darm von Säuglingen kolonisieren, hängt außer vom Entbindungsmodus auch von der Ernährung ab. Schon das Zufüttern von Er- satzmilch scheint die Zusammensetzung zu verändern.}

D ie Empfehlung, Neugeborene möglichst exklusiv zu stillen, erhält jetzt auch aus der Mikrobiomforschung Unterstützung. Nach Ergebnissen einer prospektiven Studie haben Säuglinge, die zusätzlich Ersatzmilch bekommen, eine ähnliche Darmbesiedlung wie Säuglinge mit reiner Flaschennahrung. Die ernährungsabhängigen Unterschiede in der Darmflora sind der Untersuchung zufolge jedoch geringer als die Unterschiede, die mit dem Geburtsweg zusammenhängen.

An der Studie waren 102 reifgeborene Säuglinge beteiligt, von denen 70 auf natürlichem Weg und 32 per Sectio zur Welt gekommen waren. 70 wurden aus- schließlich gestillt, 26 erhielten Muttermilch und Formulanahrung, die übrigen sechs nur Fertigmilch. Im Alter von sechs Wochen wurde in Stuhlproben mittels Sequenzierung der bakteriellen 16S-rRNA-Gene die Zusammensetzung des Darmmikrobioms bestimmt. Dabei wurden insgesamt 241 Bakteriengattungen nachgewiesen. Über $90 \%$ der sequenzierten DNA stammten allerdings von nur zehn Gattungen; allein Bacteroides und Bifidobakterien machten schon etwa die Hälfte aus.

Wie in früheren Studien zeigte sich auch in der US-amerikanischen Kohorte eine deutliche Assoziation zwischen Entbindungsmodus und Art der Darm-

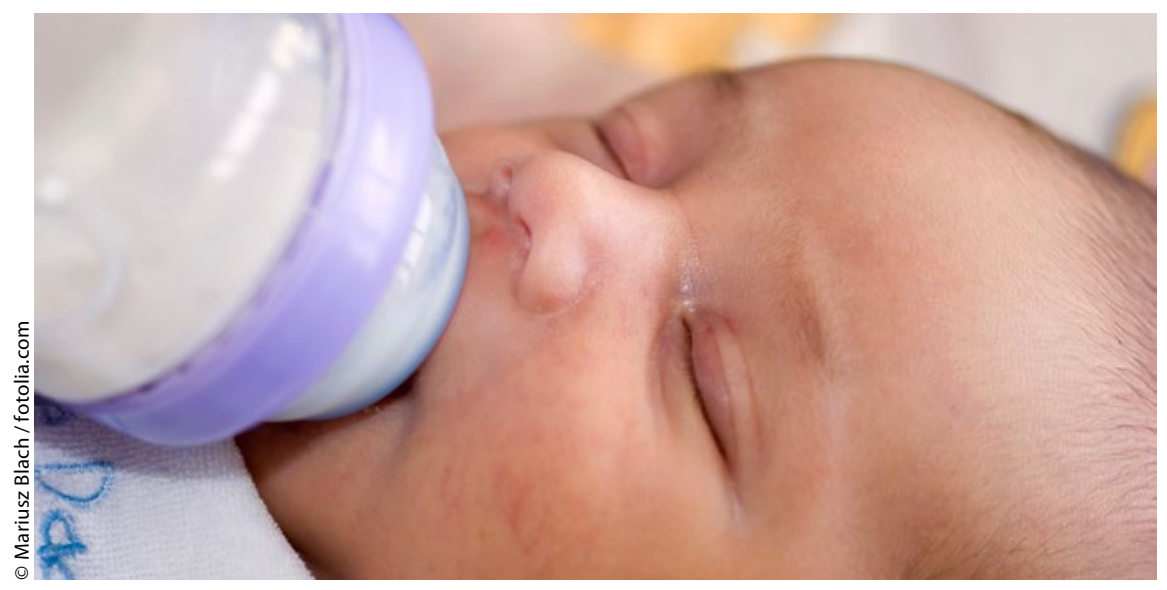

Quelle von Übergewicht?

flora ( $\mathrm{p}<0,001$ ). Dieser Zusammenhang bestand unabhängig von der Ernährung der Säuglinge. Darüber hinaus war aber auch die Ernährung mit dem Mikrobiom assoziiert. In paarweisen Vergleichen beschränkte sich der Unterschied allerdings auf reine Stillkinder in der Gegenüberstellung mit Kindern, die entweder nur Flaschenmilch oder Muttermilch plus Flaschenmilch erhielten. Kinder mit zusätzlicher Formulanahrung hatten dagegen kein signifikant anderes Mikrobiom als Kinder, die nur Fertigmilch bekamen. Generell waren die ernährungsassoziierten Mikrobiomdifferenzen geringer als die Differenzen im Zusammenhang mit dem Geburtsweg.

Bei vaginaler Entbindung war verglichen mit Kaiserschnitten der Anteil von Bacteroides und Pektobakterien erhöht und der von Staphylokokken, Rothiaund Propionibakterien vermindert. Säuglinge, die nur Muttermilch bekamen, beherbergten vor allem weniger Laktokokken als Säuglinge mit Formulanahrung.

Abweichungen in der mikrobiellen Besiedelung des Darms werden heute mit verschiedensten Störungen von der Clostridium-difficile-Infektion bis $\mathrm{zu}$ Stoffwechsel- und neurologischen Erkrankungen in Verbindung gebracht. Es ist daher vorstellbar, dass die Darmflora $\mathrm{zu}$ einem gewissen Grad auch das vermehrte Auftreten von Adipositas, Asthma und Typ-1-Diabetes nach Kaiserschnitten bzw. den Schutz vor Asthma, Übergewicht und Diabetes bei Stillkindern vermittelt.

(bs)

Madan JC et al. Association of Cesarean Delivery and Formula Supplementation With the Intestinal Microbiome of 6-Week-Old Infants. JAMA Pediatr 2016, online 11. Januar 